\title{
The status of dental caries and related factors in a sample of Iranian adolescents
}

\author{
Amir H Pakpour ${ }^{1}$, Alireza Hidarnia ${ }^{1}$, Ebrahim Hajizadeh ${ }^{2}$, Santhosh Kumar ${ }^{3}$, Adrian-Paul Harrison ${ }^{4}$ \\ ${ }^{1}$ Department of Health Education, School of Medical Sciences, Tarbiat Modares University, Tehran, I.R.Iran \\ ${ }^{2}$ Department of Biostatistics, School of Medical Sciences, Tarbiat Modares University, Tehran, I.R.Iran \\ ${ }^{3}$ Department of Preventive and Community Dentistry, Vishnu Dental College, Bhimavaram, Andhra Pradesh 534202, India \\ ${ }^{4}$ Faculty of Life Sciences, IBHV, Copenhagen University, Denmark
}

Correspondence:

Department of Health Education,

Tarbiat Modares University, Tehran, Iran.

P.O.Box: 14115-331,

Hidarnia@modares.ac.ir

Received: 22/04/2010

Accepted: 04/06/2010

\author{
Pakpour AH, Hidarnia A, Hajizadeh E, Kumar S, Harrison AP. The status \\ of dental caries and related factors in a sample of Iranian adolescents. \\ Med Oral Patol Oral Cir Bucal. 2011 Sep 1;16 (6):e822-7. \\ http://www.medicinaoral.com/medoralfree01/v16i6/medoralv16i6p822.pdf

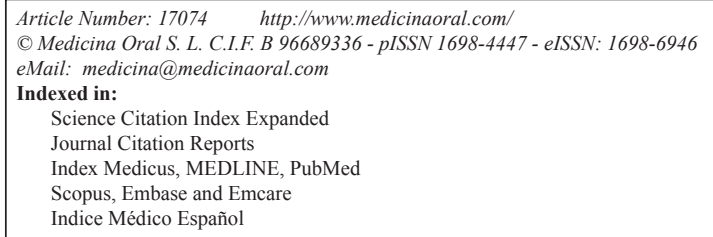

\begin{abstract}
Objective: To describe the status of dental caries in a sample of Iranian adolescents aged 14 to 18 years in Qazvin, and to identify caries-related factors affecting this group.

Study design: Qazvin was divided into three zones according to socio-economic status. The sampling procedure used was a stratified cluster sampling technique; incorporating 3 stratified zones, for each of which a cluster of school children were recruited from randomly selected high schools. The adolescents agreed to participate in the study and to complete a questionnaire. Dental caries status was assessed in terms of decayed teeth (DT), filled teeth (FT) and decayed, missing and filled teeth (DMFT). A multivariate regression analysis was used to determine statistically significant associations between DMFT and other variables.

Results: The study sample comprised 380 adolescents, 188 (49.5\%) being male. The mean age of the adolescents was $15.42(\mathrm{SD}=1.1)$ years, and the mean DMFT was $2.61(\mathrm{SD}=1.89)$. Boys had significantly higher DMFT scores than girls $(\mathrm{P}<0.05)$. The multivariate regression analyses revealed a significant relation between high DMFT scores and such variables as increasing age, male gender, lower levels of parental education, higher family income, lower frequency of tooth brushing and dental flossing, having a history of no visits to the dentist, and bad perception of own oral health.

Conclusions: The present study reveals that Iranian adolescents have a poor oral hygiene, as very few subjects brush and floss their teeth on a regular basis. Although the incidence of caries was found to be moderate, it was influenced by demographic factors such as age and gender in addition to socio-behavioral variables such as family income, the level of education attained by parents, the frequency of dental brushing and flossing, and both the frequency and type of visit to a dentist.
\end{abstract}

Key words: Oral health, DMFT, adolescents, Qazvin. 


\section{Introduction}

Oral health plays a key role in general health (1) and according to the WHO it is defined as 'being free of chronic mouth and facial pain, oral and throat cancer, oral sores, birth defects and other diseases and disorders that affect the mouth and oral cavity" (2). Moreover, the general surgeon of the United States writes that oral health includes the entire oral-facial complex and is more far ranging than just the health of the teeth. Having a good oral health enables individuals to communicate effectively, to enjoy food, to speak well, to enjoy a higher quality of life, and to have both a higher self-esteem and social confidence $(3,4)$. On the other hand, oral diseases cause serious long-term problems regarding both social (e.g. social confidence), and physical (e.g. heart disease) aspects (5-9). However, despite considerable improvement in the field of oral health throughout the world, oral health problems still persist both in developed and developing countries (10).

Nearly $20 \%$ of all people in the world are classified as being adolescents (11). Adolescence is marked by increasing involvement in health risk behaviors, for example alcohol and drug use, smoking, sexual behaviors, delinquency and behaviors that result in intentional or unintentional injuries (12). Moreover, adolescence is a critical period in an individual life with regard to health behavior, since it is a time when many personal qualities are acquired or consolidated. Empirical findings suggest that an adolescent's affiliation with friends who engage in risk behavior forms a strong predictor of an adolescents own health-risk behavior (12).

More than half of adolescents throughout the world suffer from some form of oral disease (11). Indeed, oral disease causes a number of problems in adolescents as they lose an estimated 52 million hours of school time each year due to dental problems and related care (13-14). Despite a general reduction in dental caries in all ages, studies show that it remains high during adolescence since approximately 60 to 90 percent of school-age children suffer from dental caries in developed countries (15). Indeed the Eastern Mediterranean region, which also includes Iran, has the highest mean for decayed, missing and filled teeth (DMFT) of any country in the Mediterranean region (16). Indeed some studies have shown that the level of oral health in Iran is low, as there is a high rate of untreated caries and an increasing incidence of smoking among adolescents (16-17). Unfortunately there is a lack of systematic data in Iran, preventing any measure of long-term oral health status and oral diseases (16). It is therefore crucial that the oral health status of adolescents in Iran be assessed as they are an important and high-risk group. Moreover, adolescence is a period during which individuals establish behaviors that are more often than not retained throughout ones life.

Thus, the present study has chosen to describe the status of dental caries in a sample of Iranian adolescents aged from 14 to 18 years in Qazvin, and to identify related factors that affect dental caries within this group.

\section{Materials and Methods}

Qazvin (a city close to Tehran, Iran) was divided into three zones according to socio- economic status (SES). Adolescents attending high schools in Qazvin numbered some 10,842 . The required sample size needed for this study was computed using the equation: $\mathrm{n}=\mathrm{z} 2 \mathrm{P}$. $(1-\mathrm{P}) /$ d2, where " $n$ " was the sample size, "P" was the estimated prevalence proportion observed in a pilot study $(0.45)$, "z" was the probability (0.975), and "d" was the standard error (0.05). Thus with these constraints and probabilities, a sample size of 380 adolescents was arrived at. The sampling procedure used was a stratified cluster sampling technique incorporating 3 stratified zones, for each of which a cluster of school children were recruited from randomly selected high schools. The number of high schools in zones 1, 2 and 3 were 13, 16 and 15 , respectively.

Subsequently, 380 adolescents were recruited to this study. The adolescents agreed to participate and complete a questionnaire. The questionnaire was distributed by the first author. All adolescents gave their informed consent. The study was approved by both the Ethics Committee of Tarbiat Modares University and the Organization for Education at Qazvin in 2009.

-Measurements:

The questionnaire comprised some questions including age, gender, father and mother's level of education, family income, dental visits, type of dental visit, selfassessment of oral health and frequency of tooth brushing and dental flossing.

The adolescents were asked to indicate their gender (1 for girl and 2 for boy). The father and mother's level of education was assessed in terms of the years of education. The monthly family income was measured using a three-point scale $[1=$ low $(0-500 \$), 2=$ moderate $(500$ $800 \$), 3=\operatorname{high}(>800 \$)]$. The frequency of tooth brushing was assessed on a six-point scale $(1=$ never, $2=$ less than a month $3=$ less than a week, $4=$ once a week, $5=$ once a day and $6=$ twice a day). The use of dental floss was measured using a five-point scale $(1=$ never, $2=$ less than a month $3=$ less than a week, $4=$ once a week and $5=$ once a day). Furthermore, adolescents were asked to indicate their oral health status using a threepoint scale $(1=$ poor, $2=$ average and $3=$ good $)$. A history of dental visits was taken based on three categories $(1=$ never been to a dentist, $2=$ more than 12 months ago, and $3=$ within the last 12 months). Finally, the nature or type of the last dental visit made by adolescents was noted according to a two category system ( $1=$ planned visit, and $2=$ acute visit).

A clinical examination for caries was done using the 
DMFT index. DMFT in the subjects was assessed by a single examiner, and the intra-examiner reliability for caries status (Kappa statistic) was 0.94. The clinical dental examination was conducted in the schools on a comfortable chair with the aid of a headlamp, a mouth mirror and a WHO probe (18).

-Statistical analysis

Statistical analysis was performed by SPSS, version 16.0. In order to compare two groups a Student's unpaired ttest was used. If there were more than two groups, a oneway ANOVA followed by a Tukey test was performed for assessment of group comparisons. A Spearman correlation was used to assess any correlation between the SES information provided by the students and the SES classification used in the sample selection process. Finally, a multivariate regression analysis was performed to estimate the linear relation between dependent variables (DMFT) and various independent variables (age, gender, mother and father's level of education, family income, tooth brushing, dental flossing, self assessment of oral health, the time since the last dental visit, and the nature or type of the last dental visit).

\section{Results}

Of the adolescents, 188 were male (49.5\%) and the majority brushed their teeth once a day (46.3\%). The mean age of the adolescents was 15.42 years, and most of them did not use dental floss (53.7\%). The mean number of years of education taken by the subjects mother's and father's was 6.44 and 7.94 years, respectively. The demographic characteristics of the adolescents are shown in table 1.

Table 2 compares the DMFT values of the adolescents with respect to their gender. The mean DMFT was $2.62(\mathrm{SD}=1.89)$ and there was a significant difference between the two genders, boys had a higher incidence of caries than girls $(\mathrm{P}<0.05)$. The differences between genders were seen for all of the components of DMFT with the exception of Filled Teeth $(\mathrm{FT})(\mathrm{P}<0.05)$. An intact dentition (DMFT $=0$ ) was found in $20.0 \%$ of the subjects, $21.3 \%$ of the boys and $18.8 \%$ of the girls.

A Spearman correlation test showed that monthly family income and the SES classification used in the sample selection process were highly correlated $(r=0.727$, $\mathrm{P}<0.001)$. There was also a significant difference between the SES categories for DMFT and its components (table 2).

A one way ANOVA showed that the age of the adolescents had a significant effect on the DMFT value, as with increasing age the DMFT value increased $(\mathrm{P}<0.05)$. On the other hand, adolescents living in a family with a high income had a greater incidence of caries compared with those living in a family with either a low or moderate income $(\mathrm{P}<0.001)$ (table 2$)$.

Regarding oral health behavior in the adolescents, it
Table 1. Demographic characteristics of the adolescents recruited in this study.

\begin{tabular}{|l|c|}
\hline Age (mean \pm SD) & n (\%) \\
\hline Gender & $15.42(1.1)$ \\
\hline Male & $188(49.5 \%)$ \\
\hline Female & $192(50.5 \%)$ \\
\hline Father's education (year; mean.SD) & $6.44(3.62)$ \\
\hline Mother's education (year; mean.SD) & $7.94(4.03)$ \\
\hline Tooth brushing & \\
\hline Twice a day & $69(18.2 \%)$ \\
\hline Once a day & $176(46.3 \%)$ \\
\hline Once a week & $52(13.7)$ \\
\hline Less than a week & $29(7.6 \%)$ \\
\hline Less than a month & $29(7.6 \%)$ \\
\hline Never & $25(6.6 \%)$ \\
\hline Dental flossing & \\
\hline Once a day & $32(8.4)$ \\
\hline Once a week & $50(13.2 \%)$ \\
\hline Less than once a week & $38(10 \%)$ \\
\hline Less than once a month & $56(14.7 \%)$ \\
\hline Never & $204(53.7 \%)$ \\
\hline Monthly family income & $166(32.6 \%)$ \\
\hline $0-500 \$$ (low) & $90(23.7 \%)$ \\
\hline $500-800 \$(m o d e r a t e)$ & \\
\hline$>800 \$($ high) & \\
\hline Age (mean $\pm S D)$ & \\
\hline
\end{tabular}

was observed that DMFT and all its components were higher in the adolescents who brushed their teeth less frequently than those who brushed their teeth on a more regular basis $(\mathrm{P}<0.001)$.

Furthermore, DMFT values were significantly different with respect to flossing habit. The incidence of caries in subjects who never flossed was approximately twice that of individuals who flossed once a day, as demonstrated in table 3. $(\mathrm{P}<0.05)$

All of the caries components were associated with perceived oral health status as adolescents who reported their oral health status as being "good" had a lower DMFT score $(\mathrm{P}<0.001)$.

Table 3 demonstrates that the mean DMFT values of the adolescents with a history of a recent dental visit, was significantly higher compared to those who had never been to the dentist $(\mathrm{P}<0.001)$. All of the caries components were higher among the adolescents who had seen a dentist compared to those who had never seen a dentist, whilst the type of dental visit was not found to be associated with caries components, apart from, that is, DT. 
Table 2. Mean caries indices in relation to age, family income, SES Zones and gender.

\begin{tabular}{|c|c|c|c|c|}
\hline & DT & MT & FT & DMFT \\
\hline & Mean (SD) & Mean (SD) & Mean (SD) & Mean (SD) \\
\hline \multicolumn{5}{|l|}{ Age } \\
\hline $14(\mathrm{n}=80)$ & $1.09(0.94) * 0+t$ & $0.30(0.48) * 0+t$ & $0.87(0.63) \dagger+$ & $2.19(1.72) * 0+t$ \\
\hline $15(n=162)$ & $1.15(0.91)^{\circ}+\hbar$ & $0.34(0.46)^{\circ} \dagger t$ & $0.87(0.72) \dagger+$ & $2.31(1.63)^{\circ}+t$ \\
\hline $16(n=57)$ & $1.28(1.08)+t$ & $0.42(0.56)+t$ & $0.88(0.74)$ & $2.56(1.85)+t$ \\
\hline $17(\mathrm{n}=60)$ & $1.35(1.09) \ddagger$ & $0.47(0.61)+$ & $0.89(0.75)$ & $2.69(2.00)+$ \\
\hline $18(n=21)$ & $1.42(1.06)$ & $0.52(0.63)$ & $0.89(0.71)$ & $2.85(1.94)$ \\
\hline \multicolumn{5}{|c|}{ Monthly family income } \\
\hline Low $(n=124)$ & $1.11(1.02) * \circ$ & $0.33(0.50) * \circ$ & $0.77(0.74) * \circ$ & $2.22(1.82) * \circ$ \\
\hline Moderate $(n=166)$ & $1.25(0.99)^{\circ}$ & $0.43(0.60)^{\circ}$ & $0.86(0.71)^{\circ}$ & $2.54(1.82)^{\circ}$ \\
\hline High $(n=90)$ & $2.46(0.87)$ & $0.71(0.68)$ & $1.5(0.56)$ & $4.68(1.82)$ \\
\hline \multicolumn{5}{|l|}{ SES zones } \\
\hline Zone $1(n=126)$ & $1.15(1.05)^{\circ}$ & $0.34(0.50) * \circ$ & $0.78(0.74) * \circ$ & $2.27(1.85) * \circ$ \\
\hline Zone $2(n=127)$ & $1.17(0.96)$ & $0.40(0.55)$ & $0.85(0.73)$ & $2.42(1.75)$ \\
\hline Zone $3(n=127)$ & $1.60(1.07)$ & $0.52(0.67)$ & $1.02(0.73)$ & $3.15(1.96)$ \\
\hline \multicolumn{5}{|l|}{ Gender } \\
\hline Boys $(n=188)$ & $1.42(1.11) *$ & $0.48(0.64) *$ & $0.89(0.75) *$ & $2.81(2.02) *$ \\
\hline Girls (n=192) & $1.19(0.97)$ & $0.35(0.51)$ & $0.87(0.71)$ & $2.43(1.74)$ \\
\hline
\end{tabular}

$* \mathrm{p}<0.05$ vs. group 2 (Tukey comparison between groups); ${ }^{\circ} \mathrm{p}<0.05$ vs. group 3 (Tukey comparison between groups); $\dagger \mathrm{p}<$ 0.05 vs. group 4 (Tukey comparison between groups); $\$$ p $<0.05$ vs. group 5 (Tukey comparison between groups).

A multivariate regression analysis was performed to identify factors associated with DMFT. The multivariate model did not reduce the number of statistically significant associations of demographic characteristics with oral health behavior and incidence of caries, Furthermore, the results showed that the level of education attained by the subjects father's and mother's had a negative effect on DMFT, as illustrated in table 4. In other words, dental caries was found in the adolescents whose parent's had had a low level of education.

\section{Discussion}

A lack of updated data on the oral health of adolescents makes a longitudinal analysis of social and health related trends difficult in Iran. The present study assessed dental caries status, oral health behavior and related factors among a sample of Iranian adolescents in Qazvin. The present study showed that mean DMFT among a sample of Iranian adolescents was 2.61, which is in accordance with a DMFT of 2.1 reported by Yazdani et al. among 15 year old Iranian adolescents (19). A study in Spain reported a mean DMFT of 1.84 for adolescents, which is far less comparable with the mean DMFT of 2.61 observed in the present study (20). This difference in the incidence of caries between Spain and Iran could be attributed to an ever increasing level of sugar consumption in Iran, since the annual sugar consumption per individual has increased from $25.1 \mathrm{~kg}$ in 1991 to $30.8 \mathrm{~kg}$ in 2005, an increase of some $22 \%$ (21).

This study has shown that family income is significantly related to the incidence of caries. Moreover, the results show that there are social disparities in accessibility to oral health care. Families with a high monthly income are able to buy more sweets and snacks than others with a lower income, which could be a contributing factor to a greater incidence of caries in this group. Similar findings were reported by Jürgensen and Petersen (22).

In general, SES, which is measured according to family income and the level of parental education, has a strong confounding effect on the incidence of dental caries. Moreover, family income and the level of parental education were found to have a different effect on the incidence of dental caries since family income had a positive effect and level of parental education had negative effect on DMFT values. A possible explanation for this difference could be that parental education is not an exclusive factor in terms of defining SES status, rather it is income and type of occupation that serve as more deterministic factors of SES status. In support of this explanation, the results of this study show that family income is highly correlated with the SES zones described in this work.

On the other hand, the level of education attained by the parent's had a positive effect on the incidence of car- 
Table 3. Dental caries incidence and its component factors e.g. frequency of brushing and flossing, dental visits and self-assessment of oral health status.

\begin{tabular}{|c|c|c|c|c|}
\hline & DT & MT & FT & DMFT \\
\hline & Mean (SD) & Mean (SD) & Mean (SD) & Mean (SD) \\
\hline \multicolumn{5}{|l|}{ Tooth brushing } \\
\hline Twice a day $(n=69)$ & $0.66(0.91) * \circ+\bullet$ & $0.24(0.43) * \circ+\bullet$ & $0.55(0.71) * 0+\dagger^{\bullet}$ & $1.47(1.74) * \circ \dagger+$ \\
\hline Once a day $(n=176)$ & $1.18(0.91)^{\circ} \dagger+\bullet$ & $0.39(0.56)^{\circ}+\mathrm{f}^{\circ}$ & $0.82(0.65)^{\circ} \uparrow^{\bullet}$ & $1.65(1.66)^{\circ}+\dagger^{\bullet}$ \\
\hline Once a week $(n=52)$ & $1.62(0.97) \dagger+\bullet$ & $0.50(0.64) \dagger^{\bullet}$ & $1.15(0.72) \dagger+\bullet$ & $1.75(1.82) \div$ \\
\hline Less than a week $(n=29)$ & $1.68(0.94)+\bullet$ & $0.68(0.76)+\bullet$ & $1.24(0.72) \div \cdot$ & $1.83(1.60)^{\bullet}$ \\
\hline Less than a month $(\mathrm{n}=29)$ & $1.80(1.1)^{\bullet}$ & $0.48(0.57) \bullet$ & $0.82(0.80)^{\bullet}$ & $2.89(2.18)$ \\
\hline Never $(n=25)$ & $2.12(1.05)$ & $0.56(0.65)$ & $1.34(0.71)$ & $2.18(1.87)$ \\
\hline \multicolumn{5}{|l|}{ Dental flossing } \\
\hline Once a day $(\mathrm{n}=32)$ & $0.71(0.95) * 0+t$ & $0.30(0.53) \dagger+$ & $0.53(0.67) * \circ+\dagger$ & $1.59(1.91) * 0+t$ \\
\hline Once a week $(n=50)$ & $1.00(0.92)^{\circ}+t$ & $0.31(0.60) \dagger+$ & $0.82(0.64) \dagger+$ & $2.22(1.90)^{\circ}+t$ \\
\hline Less than once a week $(n=38)$ & $1.31(0.93) \dagger+$ & $0.32(0.52) \dagger+$ & $0.78(0.70) \dagger+$ & $2.42(1.53) \dagger+$ \\
\hline Less than once a month $(n=56)$ & $1.40(1.07) \dagger$ & $0.41(0.61) \ddagger$ & $1.00(0.66)$ & $2.75(1.92) \dagger$ \\
\hline Never $(n=204)$ & $1.58(1.06)$ & $0.62(0.58)$ & $0.94(0.73)$ & $3.21(1.75)$ \\
\hline \multicolumn{5}{|l|}{ Self-assessment of oral health } \\
\hline Good $(n=118)$ & $0.79(1.00) * \circ$ & $0.22(0.44) * \circ$ & $0.34(0.52) * \circ$ & $1.37(1.67) * \circ$ \\
\hline Average $(n=174)$ & $1.35(0.89)^{\circ}$ & $0.39(0.56)^{\circ}$ & $1.01(0.62)^{\circ}$ & $2.76(1.57)^{\circ}$ \\
\hline Poor $(\mathrm{n}=88)$ & $1.92(1.07)$ & $0.75(0.66)$ & $1.35(0.74)$ & $4.0(1.68)$ \\
\hline \multicolumn{5}{|l|}{ Time since last visit } \\
\hline Within the last 12 months $(\mathrm{n}=74)$ & $0.42(0.85) * \circ$ & $0.33(0.47) * \circ$ & $0.42(0.11) * \circ$ & $0.78(1.33)^{* \circ}$ \\
\hline More than 12 months ago $(n=137)$ & $1.23(0.06)^{\circ}$ & $0.43(0.63)$ & $0.66(0.12)^{\circ}$ & $2.47(1.82)^{\circ}$ \\
\hline Never been to a dentist $(n=169)$ & $1.48(1.12)$ & $0.45(0.58)$ & $0.74(0.05)$ & $2.94(1.72)$ \\
\hline \multicolumn{5}{|l|}{ Type of visits } \\
\hline Planned visits $(n=83)$ & $1.28(1.03) *$ & $0.38(0.66)$ & $0.88(0.73)$ & $2.59(1.89)$ \\
\hline Acute visits $(\mathrm{n}=128)$ & $1.80(1.04)$ & $0.42(0.58)$ & $0.90(0.70)$ & $3.09(1.87)$ \\
\hline
\end{tabular}

${ }^{*} \mathrm{p}<0.05$ vs. group 2 (Tukey comparison between groups); ${ }^{\circ} \mathrm{p}<0.05$ vs. group 3 (Tukey comparison between groups); $\dagger p<0.05$ vs. group 4 (Tukey comparison between groups); $₫$ p $<0.05$ vs. group 5 (Tukey comparison between groups); $\bullet p<0.05$ vs. group 6 (Tukey comparison between groups).

Table 4. Multivariate regression analyses of the dependant variable DMFT against sociodemographic and behavioural factors.

\begin{tabular}{|l|c|c|c|c|}
\hline & B & B & \multicolumn{2}{|c|}{ CI } \\
\hline Age & & & Lower & Upper \\
\hline Gender & $0.102^{*}$ & 0.168 & 0.002 & 0.333 \\
\hline Mother's education & $-0.105^{*}$ & -0.397 & -0.779 & -0.016 \\
\hline Father's education & $-0.225^{* *}$ & -0.118 & -0.169 & -0.066 \\
\hline Family income & $-0.231^{* *}$ & -0.109 & -0.155 & -0.062 \\
\hline Tooth brushing & $0.260^{* *}$ & 0.831 & 0.518 & 1.143 \\
\hline Dental flossing & $-0.336^{* *}$ & -0.451 & -0.578 & -0.323 \\
\hline $\begin{array}{l}\text { Self-assessment of oral } \\
\text { health }\end{array}$ & $-0.175^{* *}$ & -0.240 & -0.376 & -0.103 \\
\hline Time since last dental visit & $-0.513^{* *}$ & -1.329 & -1.55 & -1.104 \\
\hline Type of dental visit & $-0.198^{* *}$ & -0.469 & -0.704 & -0.233 \\
\hline
\end{tabular}

$* \mathrm{p}<0.05 ; * \mathrm{p}<0.01 ; \mathrm{R} 2=0.163$; Adjusted R2 $=0.143$; B, standardized regression coefficients; B, unstandardized regression coefficients; $95 \% \mathrm{CI}, 95 \%$ confidence interval. 
ies. It is assumed, therefore that more highly educated people demonstrate a more positive behavior towards dental health, perhaps eating fewer sweet foods, brushing their teeth more often and visiting their dentist on a more regular basis. Indeed, a study has shown that parents play a major role in terms of preventing the incidence of dental caries in their children (23).

The present study has observed a significant association between gender and the incidence of caries, since girls had a lower DMFT score than boys. It is assumed, however, that girls are more concerned about oral health related issues than boys. Moreover, these findings are consistent with previous published data (22-24).

The frequency of tooth brushing and flossing had a significant effect on DMFT scores. Subjects brushing and flossing their teeth less frequently had a greater incidence of caries. However, less than one-fifth of the study sample (18.2\%) reported that they brushed their teeth twice-daily, which shows that there exists a relatively poor brushing habit among Iranian adolescents.

Finally, this study revealed a consistency between DMFT scores and the subjective evaluation of ones own oral health. Similar findings have been reported from studies undertaken in both Laos and Brazil (22-25).

The findings indicate that untreated dental caries has a major effect on perceived oral health in Iranian adolescents. The time since subjects last visited a dentist as well as the nature or type of that dental visit had a significant effect on DMFT and its components. The mean DMFT among those subjects who had never visited a dentist was approximately three times that of those who had been to a dentist within the last 12 months. This suggests that adolescents who regularly visit a dentist are more sensitive to, or aware of their own oral health, and that regular checkups can help to preserve intact teeth from caries attack.

\section{Conclusions}

The present study affirms that Iranian adolescents exhibit behavior that results in poor oral hygiene, primarily as the result of infrequent brushing and flossing. Though the caries experience was moderate, it was influenced by demographic factors e.g. age and gender, as well as such socio-behavioral variables as family income, level of parental education, frequency of dental brushing and flossing, and both the frequency and type of visit to a dentist.

\section{References}

References with links to Crossref - DOI

1. Moynihan PJ. The role of diet and nutrition in the etiology and prevention of oral diseases. Bull World Health Organ. 2005;83:694-9.

2. Petersen PE, Bourgeois D, Bratthall D, Ogawa H. Oral health information systems--towards measuring progress in oral health promotion and disease prevention. Bull World Health Organ. 2005;83:68693.
3. Crall JJ. Oral health policy development since the Surgeon General's Report on Oral Health. Acad Pediatr. 2009;9:476-82.

4. Locker D. Measuring oral health: a conceptual framework. Community Dent Health. 1988;5:3-18.

5. Watt RG. Strategies and approaches in oral disease prevention and health promotion. Bull World Health Organ. 2005;83:711-8.

6. Davenport ES, Williams CE, Sterne JA, Sivapathasundram V, Fearne JM, Curtis MA. The East London Study of Maternal Chronic Periodontal Disease and Preterm Low Birth Weight Infants: study design and prevalence data. Ann Periodontol. 1998;3:213-21.

7. Genco R, Offenbacher S, Beck J. Periodontal disease and cardiovascular disease: epidemiology and possible mechanisms. J Am Dent Assoc. 2002;133 Suppl:14S-22S.

8. Offenbacher S, Katz V, Fertik G, Collins J, Boyd D, Maynor G, et al. Periodontal infection as a possible risk factor for preterm low birth weight. J Periodontol. 1996;67:1103-13.

9. Slavkin HC. Does the mouth put the heart at risk? J Am Dent Assoc. 1999;130:109-13.

10. Petersen PE. The World Oral Health Report 2003: continuous improvement of oral health in the 21st century--the approach of the WHO Global Oral Health Programme. Community Dent Oral Epidemiol. 2003;31 Suppl 1:3-23.

11. Petersen PE, Bourgeois D, Ogawa H, Estupinan-Day S, Ndiaye C. The global burden of oral diseases and risks to oral health. Bull World Health Organ. 2005;83:661-9.

12. Prinstein MJ, Boergers J, Spirito A. Adolescents' and their friends'health-risk behavior: factors that alter or add to peer influence. J Pediatr Psychol. 2001;26:287-98.

13. Crowley E, O’Brien G, Marcenes W. School league tables: a new population based predictor of dental restorative treatment need. Community Dent Health. 2003;20:78-82.

14. Gift HC, Reisine ST, Larach DC. The social impact of dental problems and visits. Am J Public Health. 1992;82:1663-8.

15. Jones S, Burt BA, Petersen PE, Lennon MA. The effective use of fluorides in public health. Bull World Health Organ. 2005;83:670-6. 16. Pakshir HR. Oral health in Iran. Int Dent J. 2004;54:367-72.

17. Sarraf-Zadegan N, Boshtam M, Shahrokhi S, Naderi GA, Asgary $\mathrm{S}$, Shahparian M, et al. Tobacco use among Iranian men, women and adolescents. Eur J Public Health. 2004;14:76-8.

18. Pereira SM, Tagliaferro EP, Cortellazzi KL, Ambrosano GM, Mialhe FL, Meneghim Mde C, et al. Estimate of DMFT index using teeth most affected by dental caries in twelve-year-old children. Rev Saude Publica. 2009;43:179-82.

19. Yazdani R, Vehkalahti MM, Nouri M, Murtomaa H. Oral health and treatment needs among 15-year-olds in Tehran, Iran. Community Dent Health. 2008;25:221-5.

20. Almerich Silla JM, Montiel Company JM. Oral health survey of the child population in the Valencia Region of Spain (2004). Med Oral Patol Oral Cir Bucal. 2006;11:E369-81.

21. Ghassemi H, Harrison G, Mohammad K. An accelerated nutrition transition in Iran. Public Health Nutr. 2002;5:149-55.

22. Jürgensen N, Petersen PE. Oral health and the impact of sociobehavioural factors in a cross sectional survey of 12-year old school children in Laos. BMC Oral Health. 2009;9:29.

23. Weinstein P, Harrison R, Benton T. Motivating parents to prevent caries in their young children: one-year findings. J Am Dent Assoc. 2004;135:731-8.

24. Ostberg AL, Halling A, Lindblad U. Gender differences in knowledge, attitude, behavior and perceived oral health among adolescents. Acta Odontol Scand. 1999;57:231-6.

25. Pattussi MP, Olinto MT, Hardy R, Sheiham A. Clinical, social and psychosocial factors associated with self-rated oral health in Brazilian adolescents. Community Dent Oral Epidemiol. 2007;35:377-86.

\section{Acknowledgments}

We would like to thank the Organization for Education at Qazvin specially Mr. Moradi and Mrs Pakpour. 